\title{
Prevalence of severe acute malnutrition in children aged 6 -60 months admitted at mother of Christ specialist hospital Ogui, Enugu, Nigeria
}

\author{
Okwy-Nweke Chizoba, P. $^{1}$, Maduforo Aloysius, N. $^{2}$, Otiora C. ${ }^{1}$, Uche C. A. ${ }^{1}$ \\ ${ }^{1}$ Department of Nutrition and Dietetics,University of Nigeria Teaching Hospital Ituku-Ozalla, Enugu State, Nigeria \\ ${ }^{2}$ Department of Nutrition and Dietetics Research, PMAN International Health Services, Abuja FCT, Nigeria \\ Email address: \\ okwynwekec@gmail.com (Okwy-Nweke C. P.), preciousman179@yahoo.com (Maduforo A. N.)
}

\section{To cite this article:}

Okwy-Nweke Chizoba, P., Maduforo Aloysius, N., Otiora C., Uche C. A.. Prevalence of Severe Acute Malnutrition in Children Aged 6 60 Months Admitted at Mother of Christ Specialist Hospital Ogui, Enugu, Nigeria. European Journal of Preventive Medicine.

Vol. 2, No. 4, 2014, pp. 45-51. doi: 10.11648/j.ejpm.20140204.12

\begin{abstract}
Background: Prevalence of severe acute malnutrition in children aged 6 - 60 months in mother of Christ hospital Ogui Enugu was studied. The study was aimed: to determine the social demographic profile of severely malnourished children and/or parents of children with severe acute malnutrition, to determine the risk factors for severe acute malnutrition in admitted children with Severe Acute Malnutrition (SAM) and to know the prevalence of wasting, stunting and under-weight of children from 6 - 60months. Methodology: Random selection was used to select the population studied. The data collected include the patients' mothers' biography, patients anthropometry, biochemical results and family size. The NCHS reference standard were used to determined the nutritional status of the children.SPSS version 16 was used to determine the descriptive statistics (percentages and frequencies).Result: The result of the survey revealed that there was a relationship between education attainment of mothers and child's conditional status which was significant $(p<0.05)$. Prevalence of severe acute malnutrition occurs mainly in families that have limited access to nutritious food and are living in unhygienic condition, which increases risk of repeated infections. Malnutrition was common in the first and second year of life as a result of inadequate breastfeeding of the child and high rate of infection. The study revealed that large households have significant $(\mathrm{P}<0.05)$ influence on the nutritional status of the children than smaller household. Conclusion: In this study results indicated that malnutrition is a problem among children in the area. The prevalence of malnutrition such as wasting, stunting and underweight was high within the ages of 0-11 months and 12-17 months. Child feeding practices were inadequate. Mother's characteristics and household feeding characteristics appear to influence children's nutritional status. Effort to improve feeding practices and to relieve the constraints to the adoption of exclusive breastfeeding and optimal feeding practices will have significant effects on child nutritional status in the population.
\end{abstract}

Keywords: Prevalence, Severe, Acute, Malnutrition, Children

\section{Introduction}

Severe acute malnutrition remains a major killer of children under five years of age (1). The under-5 mortality rate decreased from 201 deaths per 1,000 live births in 2003 Nigeria Demographic and Health Survey (NDHS) to 128 deaths per 1,000 live births in the 2013 NDHS (2). However, Nigeria still has a long way to go to achieve the MDG target of reducing the under-5 mortality to 64 deaths per 1,000 live births and the infant mortality to 30 deaths per 1,000 live births by 2015 (3).The estimated infant mortality rate in the 2003 NDHS was 100 deaths per 1,000 live births, which decreased to 75 deaths per 1,000 live births in the 2008 NDHS and further to 69 deaths per 1,000 live births in the 2013 NDHS. The pattern shows that about 29 percent of deaths under age 5 occur during the neonatal period ( 37 deaths per 1,000 live births), and 24 percent occur during the post-neonatal period (31 deaths per 1,000 live births) (2). Until recently, treatment has been restricted to facility-based approaches, greatly limiting its coverage and impact. New evidence suggests that large numbers of children with severe acute malnutrition can be treated in 
their communities without being admitted to a health facility or a therapeutic feeding centre (1). The communitybased approach involves timely detection of severe acute malnutrition in the community and provision of treatment for those without medical complications with ready-to-use therapeutic foods or other nutrient-dense foods at home. If properly combined with a facility-based approach for those malnourished children with medical complications and implemented on a large scale, community- based management of severe acute malnutrition could prevent thedeaths of hundreds of thousands of children (1).

Severe acute malnutrition is defined by a very low weight for height (below $-3 \mathrm{z}$ scores of the median WHO growth standards), by visible severe wasting, or by the presence of nutritional oedema. In children aged 6-60 months, an arm circumference less than $110 \mathrm{~mm}$ is also indicative of severe acute malnutrition. Globally, it is estimated that there are nearly 20 million children who are severely acutely malnourished (1).

The NDHS survey revealed that 37 percent of children under age 5 are considered to be short for their age or stunted, while 21 percent are severely stunted (below -3SD). Eighteen percent of children are considered wasted or too thin for their height and 9 percent are severely wasted. Twenty-nine percent of children are underweight (low weight-for-age), and 12 percent are severely underweight (3).

Prevalence of Severe acute malnutrition occurs mainly in families that have limited access to nutritious food and are living in unhygienic conditions, which increase the risk of repeated infections. Thus, preventive programmes have an immense job to do in the context of poverty, and in the meantime children who already are suffering from severe acute malnutrition need treatment (1).

The recommendation to exclusively breastfeed children for the first six months of life is met for only 17 percent of children. The results also indicate that complementary foods are often introduced early in Nigeria, with 23 percent of children under age 6 months and 38 percent of children age 4-5 months consuming solid or semi-solid foods in addition to breast milk. Bottle feeding among children below age 2 is on the rise, even though it is not normally recommended. Sixteen percent of infants under age 2 months are being fed using a bottle with a nipple. This proportion rises among children age 6-8 months to 17 percent (3).

The objective of this study is to determine the prevalence of acute malnutrition in children aged6 -60 months admitted in the pediatric wards of Mother of Christ Specialist Hospital Enugu state. This is specifically aimed: to determine the social demographic profile of severely malnourished children and/or parents of children with severe acute malnutrition, to determine the risk factors for severe acute malnutrition in admitted children with SAM and to know the prevalence of wasting, stunting and underweight of children from 6 months-60months.

\section{Methodology}

\subsection{Study Area}

This study was carried out at the medical records of the Mother of Christ Specialist Hospital (MCSH)in Enugu State.

\subsection{Population Size}

All children from 6 - 60months with severe acute malnutrition admitted to pediatric wards of the Mother of Christ Specialist Hospital Enugu.

\subsection{Sample Size}

The case notes of 200 children between the ages of $6-60$ months was randomly sampled.

\subsection{Data Collection}

The data was collected from patients' folder, from each case note, some vital information that would be documented includes age of patients in months, sex,parents' occupation and other information to be collected would include;

1. The weight/length and height of child, head circumference, presence of bipedal oedema; visible severe wasting, dermatitis, presence of flaky, sparse hair, persistent diarrhea, moonfaced appearance.

2. Information on weight, height and the presence of mid upper arm circumference less than $115 \mathrm{~mm}$ in children will also be obtained and clinical history.

3. The case folders of each patient were carefully studied and the following information taken: Parents' bio-data, occupation, educational background, average monthly income/salary level. Mother nutritional knowledge was taken and feeding history.

\subsection{Data Analysis}

The questionnaire was coded and analysed using the computer programme, statistical package for social sciences (SPSS) for window version 16. The anthropometric data was analysed using anthropometric $\mathrm{Z}$ scores (WHO, 2006) and categorized using WHO Anthro software version 3.2.2 (WHO, 2011) which is designed for application of the WHO child's growth standard in individuals and population $0-60$ months.

\subsection{Mid Upper Arm Circumference}

The mid upper arm circumference was determined using aShakir's strip (arm circumference non-stretch tape) marked in appropriate colours (green, yellow and red)to the nearest $0.1 \mathrm{~cm}$. The left arm was used, it hang freely down by the side of the child, the arm half way between the point of the shoulder and the tip of the elbow was marked and the strip went round the marked point for measurement. The value was recorded in $\mathrm{cm}$, reading of less than $11.0 \mathrm{~cm} / \mathrm{red}$ was recorded as severally malnourished, between $11.0 \mathrm{~cm}-$ 
$12.5 \mathrm{~cm} /$ yellow was recorded as moderately malnourished while above 12.5 /green was normal.

\subsection{Hemoglobin $(\mathrm{Hb})$}

In the diagnosis of nutritional anemia, it is essential to measure $\mathrm{Hb}$ in blood. It is one of the most common and least expensive measurements done in a nutritional laboratory (6). Below was used as a criteria for classification (6):

Table 1. Criteria for Classification of Anaemia

\begin{tabular}{ll}
\hline $\mathrm{The} \mathrm{Hb} \geq 11.5 \mathrm{~g} / \mathrm{dl}$ and above & Non anaemic \\
$10-11 \mathrm{~g} / \mathrm{dl}$ & mild anaemic \\
$7 \leq 10 \mathrm{~g} / \mathrm{dl}$ & moderate anaemic \\
$<7 \mathrm{~g} / \mathrm{dl}$ & severe anaemic \\
\hline
\end{tabular}

\section{Results}

Table 2. Demographic/socio-economic characteristics of the children's mothers

\begin{tabular}{|c|c|c|}
\hline characteristics & Frequency $(\mathbf{N})$ & Percentage (\%) \\
\hline \multicolumn{3}{|l|}{ Occupation } \\
\hline Farmers & 23 & 11.5 \\
\hline Traders & 95 & 47.5 \\
\hline Civil Servants & 18 & 8 \\
\hline Others & 66 & 33 \\
\hline \multicolumn{3}{|c|}{ Monthly Income (Naira) of the Parents } \\
\hline None & 26 & 13 \\
\hline$\leq 7,500$ & 70 & 35 \\
\hline $7,500-12,600$ & 58 & 29 \\
\hline More than 12,600 & 46 & 23 \\
\hline \multicolumn{3}{|l|}{ Education Level } \\
\hline No Formal Education & 2 & 1 \\
\hline Primary Education & 59 & 29.5 \\
\hline Secondary Education & 120 & 60 \\
\hline Tertiary Education & 9 & 9.5 \\
\hline \multicolumn{3}{|l|}{ Household Size } \\
\hline $1-3$ Members & 49 & 24.5 \\
\hline $4-7$ Members & 97 & 48.5 \\
\hline More than 7 Members & 54 & 27 \\
\hline
\end{tabular}

Table 2 showed the socio-economic characteristics of the children mothers, the majority $(47.5 \%)$ of the mothers were traders, while $11.5 \%$ were farmers, $8 \%$ were civil servants and $33 \%$ involved in other businesses. About $35 \%$ of the mothers eared less than N7,500 per month, while $29 \%$ earned N7,500 - N12,600, 23\% earned more than N12,600 and $13 \%$ earned nothing. Only $72.5 \%$ of the fathers earned more than N12,600 while 27\% earned N7,500 - N12,600 and $0.5 \%$ earned less than N7,500. About $99 \%$ had formal education. Mothers with primary, secondary and tertiary education accounted for $29.5 \%, 60 \%$ and $9.5 \%$ respectively. Almost half (48.5\%) of the respondents were from household size of 4-7 members in the family, while $27 \%$ were from household size of more than 7 members and $24.5 \%$ were from household size of $1-3$ members.

Table 3. Complementary Feeding Frequency of Children

\begin{tabular}{lll}
\hline Complementary Foods (\%) & Number $(\mathbf{N})$ & Percentage (\%) \\
\hline Type of foods given & 3 & 1.5 \\
Plain Pap & 100 & 50 \\
Pap with Milk & 36 & 18 \\
Pap with Soya Bean & 2 & 1 \\
Pap with Egg & 4 & 2 \\
Pap with Oil/Fat & 27 & 13.5 \\
Milk only & 12 & \\
Feeding Frequency & 60 & 6 \\
Two times per day & 53 & 30 \\
Three times per day & 40 & 26.5 \\
Four times per day & 12 & 20 \\
Five times per day & 13 & 6 \\
More than five times per day & & 11.5 \\
Have not started weaning & 12 & \\
\hline
\end{tabular}

Table 3 Shows that the majority of the children were given pap with milk $(50 \%)$, pap with soya bean (18\%) and milk only $(13.5 \%)$ as complementary food. The frequency of feeding depends on the age of the child. About $30 \%$ of the children were fed three times per day, $6 \%$ fed were fed two time/day, $26.5 \%$ were fed four times/day, $20 \%$ were fed five times/day and $6.0 \%$ were fed more than five time/day.

Table 4. Breastfeeding and child feeding practices

\begin{tabular}{llll}
\hline Practice & $\begin{array}{l}\text { Male } \\
\text { N (\%) }\end{array}$ & $\begin{array}{l}\text { Female } \\
\text { N (\%) }\end{array}$ & $\begin{array}{l}\text { Total } \\
\text { N (\%) }\end{array}$ \\
\hline $\begin{array}{l}\text { Those that were exclusively } \\
\text { breastfed }\end{array}$ & $54(27)$ & $64(32)$ & $118(58)$ \\
$\begin{array}{l}\text { Those that were not } \\
\text { exclusively breastfed }\end{array}$ & $30(15)$ & $29(14.5)$ & $59(29.5)$ \\
$\begin{array}{l}\text { Those that were still } \\
\text { breastfeeding }\end{array}$ & $10(5.0)$ & $13(6.5)$ & $23(11.5)$ \\
Total & $94(47)$ & $106(53)$ & $200(100)$ \\
\hline
\end{tabular}

A total of $58 \%$ of the children were exclusively breastfed, $27 \%$ males and $32 \%$ of females. Children who were not exclusively breastfed were males (15\%) and females (14.5\%) totaling $29.5 \%$ and $11.5 \%$ were still breastfeeding at the time of admission to the hospital.

Table 5. Age of introducing complementary food

\begin{tabular}{lll}
\hline Age & Number $(\mathbf{N})$ & Percentage (\%) \\
\hline $2-3$ Months & 113 & 56.5 \\
$4-6$ Months & 56 & 28 \\
$7-9$ Months & 31 & 15.5 \\
\hline
\end{tabular}

Table 5 shows that majority $(56.5 \%)$ of the children were introduced complementary food at the age range of 2 - 
3 months, $28 \%$ started at the age of 4 - 6 months and 15.5 at $7-9$ months.

Table 6. Mothers' Characteristics and Nutritional Status of their Children

\begin{tabular}{lllll}
\hline & $\begin{array}{l}\text { Normal } \\
(\%)\end{array}$ & $\begin{array}{l}\text { Severe } \\
(\%)\end{array}$ & $\begin{array}{l}\text { Moderate } \\
(\%)\end{array}$ & $\begin{array}{l}\text { Total } \\
(\%)\end{array}$ \\
\hline No Formal Education & $1(0.5)$ & $1(0.5)$ & $0(0)$ & $2(1)$ \\
Primary Education & $35(17.5)$ & $3(1.5)$ & $21(10.5)$ & $59(29.5)$ \\
Secondary Education & $54(42)$ & $2(1)$ & $34(17)$ & $120(60)$ \\
Tertiary Education & $19(9.5)$ & $0(0)$ & $0(0)$ & $19(9.5)$ \\
Total & $139(69.5)$ & $6(3)$ & $55(27.5)$ & $200(100)$ \\
Household Size & & & & \\
$\begin{array}{l}1-3 \text { Members } \\
\text { 4-7 Members }\end{array}$ & $46(23)$ & $2(1)$ & $1(0.5)$ & $49(24.8)$ \\
More than 7 Members & $30(34.5)$ & $10(5)$ & $18(9)$ & $97(48.8)$ \\
Total & $145(72.5)$ & $26(13)$ & $29(14.5)$ & $200(100)$ \\
\hline
\end{tabular}

Table 6 shows that out of the $60 \%$ that had secondary education, $18 \%$ had malnourished children while $42 \%$ had children with normal nutritional status. Also $9.5 \%$ of the mothers with tertiary education had no malnourish child. Also, about 9\% moderately malnourished children were from a household size of 4-7 persons. The most severely malnourished children (7\%) were from household size of more than $>7$ persons.

Table 7. The nutritionalstatus of the children based on the age of introduction of complementary foods.

\begin{tabular}{lllll}
\hline $\begin{array}{l}\text { Complementary } \\
\text { Age }\end{array}$ & $\begin{array}{l}\text { Normal } \\
(\%)\end{array}$ & $\begin{array}{l}\text { Severe } \\
(\%)\end{array}$ & $\begin{array}{l}\text { Moderate } \\
(\%)\end{array}$ & $\begin{array}{l}\text { Total } \\
(\%)\end{array}$ \\
\hline $2-3$ Months & $73(36.5)$ & $7(3.5)$ & $33(16.5)$ & $3(56.5)$ \\
$4-6$ Months & $51(25.5)$ & $2(1)$ & $3(1.5)$ & $56(28)$ \\
$7-9$ Months & $8(4)$ & $4(2)$ & $19(9.5)$ & $31(15.5)$ \\
Total & $132(66)$ & $13(6.5)$ & $55(27.5)$ & $200(100)$ \\
\hline
\end{tabular}

Table 6 shows that malnutrition was more $(20 \%$ that is; Severe - 3.5\% and Moderate - $16.5 \%$ ) in children that started complementary foods at 2-3 months of age. While for those that started complementary foods at 4-6 months of age only $2.5 \%$ were malnourished. About $2 \%$ and $9.5 \%$ of those that started complementary foods at 7-9 month were severely and moderately malnourished respectively.

Table 8. Nutritional Status by Age Groups, Measured by Weight for Height (Wasting)

\begin{tabular}{llllll}
\hline Months & $\begin{array}{l}\text { Normal } \\
\text { F(\%) }\end{array}$ & $\begin{array}{l}\text { Mild } \\
\mathbf{F ( \% )}\end{array}$ & $\begin{array}{l}\text { Moderate } \\
\mathbf{F ( \% )}\end{array}$ & $\begin{array}{l}\text { Severe } \\
\mathbf{F}(\%)\end{array}$ & $\begin{array}{l}\text { Total } \\
\mathbf{N}(\%)\end{array}$ \\
\hline $0-11$ & $91(45.5)$ & $1(0.5)$ & $20(10)$ & $4(2)$ & $116(58)$ \\
$12-17$ & $20(10)$ & $0(0)$ & $9(4.5)$ & $1(0.5)$ & $30(15)$ \\
$18-23$ & $6(3)$ & $0(0)$ & $3(1.5)$ & $1(0.5)$ & $10(5)$ \\
$24-35$ & $17(8.5)$ & $0(0)$ & $3(1.5)$ & $1(0.5)$ & $21(10.5)$ \\
$36-47$ & $9(4.5)$ & $0(0)$ & $2(1)$ & $2(1)$ & $13(6.5)$ \\
$48-60$ & $6(3)$ & $0(0)$ & $1(0.5)$ & $3(1.5)$ & $10(5)$ \\
Total & $149(74.5)$ & $1(0.5)$ & $38(19)$ & $12(6)$ & $200(100)$ \\
\hline
\end{tabular}

In table 8 , about $74.5 \%$ of children had normal nutritional status, while $19 \%$ were moderately wasted, $6 \%$ were severely wasted and $0.5 \%$ was mild-under nutrition (Wasted). Under nutrition was more (12\%) in the ages of 0 -
11 month while 48-60 month of age had the least $(2 \%)$ under nutrition. About $10 \%$ and $2 \%$ of children aged $0-11$ monthswere moderately severely wasted.

Table 9. Nutritional status by age group measured by height for-age (Stunting)

\begin{tabular}{llllll}
\hline $\begin{array}{l}\text { Age Category } \\
\text { Months }\end{array}$ & $\begin{array}{l}\text { Normal } \\
\mathbf{N}(\%)\end{array}$ & $\begin{array}{l}\text { Mild } \\
\mathbf{N}(\%)\end{array}$ & $\begin{array}{l}\text { Moderate } \\
\mathbf{N}(\%)\end{array}$ & $\begin{array}{l}\text { Severe } \\
\mathbf{N}(\%)\end{array}$ & $\begin{array}{l}\text { Total } \\
\mathbf{N}(\%)\end{array}$ \\
\hline 0.11 & $86(43)$ & $4(2)$ & $17(85)$ & $9(4.5)$ & $116(58)$ \\
$12-17$ & $16(8)$ & $1(1)$ & $10(5)$ & $2(1)$ & $30(15)$ \\
$18-23$ & $6(3)$ & $0(0)$ & $3(1.5)$ & $1(0.5)$ & $10(5)$ \\
$24-35$ & $13(6.5)$ & $2(1)$ & $4(2)$ & $2(1)$ & $21(10.5)$ \\
$36-47$ & $8(4)$ & $0(0)$ & $4(2)$ & $1(0.5)$ & $13(6.5)$ \\
$48-60$ & $5(2.5)$ & $0(0)$ & $3(0.5)$ & $2(1)$ & $10(5)$ \\
Total & $134(67)$ & $8(4)$ & $41(20.5)$ & $8(4)$ & $200(100)$ \\
\hline
\end{tabular}

Table 9 above shows the fact that $67 \%$ of children were normal, $20.5 \%$ of children were moderately stunted, $4 \%$ of children were severely stunted and $4 \%$ of children were mildly stunted. About $8.5 \%$ were moderately stunted and $4.5 \%$ were severely stunted at $0-11$ months of age.

Table 10. Nutritional status by age group measured by weight-for-age (Underweight)

\begin{tabular}{llllll}
\hline $\begin{array}{l}\text { Age Category } \\
\text { Months }\end{array}$ & $\begin{array}{l}\text { Normal } \\
\mathbf{N}(\%)\end{array}$ & $\begin{array}{l}\text { Mild } \\
\mathbf{N}(\%)\end{array}$ & $\begin{array}{l}\text { Moderate } \\
\mathbf{N}(\%)\end{array}$ & $\begin{array}{l}\text { Severe } \\
\mathbf{N}(\%)\end{array}$ & $\begin{array}{l}\text { Total } \\
\mathbf{N}(\%)\end{array}$ \\
\hline 0.11 & $86(43)$ & $3(1.5)$ & $10(10)$ & $4(2)$ & $116(58)$ \\
$12-17$ & $16(8)$ & $3(1.5)$ & $10(5)$ & $5(2.5)$ & $30(15)$ \\
$18-23$ & $6(3)$ & $0(0)$ & $3(1.5)$ & $1(0.5)$ & $10(5)$ \\
$24-35$ & $16(8)$ & $0(0)$ & $3(1.5)$ & $2(1)$ & $21(10.5)$ \\
$36-47$ & $10(5)$ & $0(0)$ & $2(1)$ & $1(0.5)$ & $13(6.5)$ \\
$48-60$ & $7(3.5)$ & $0(0)$ & $2(1)$ & $1(0.5)$ & $10(5)$ \\
Total & $140(70)$ & $6(3)$ & $40(20)$ & $14(7)$ & $200(100)$ \\
\hline
\end{tabular}

Table 10 represented that $70 \%$ of the children were normal, $20 \%$ were moderately underweight, $7 \%$ were severely underweight and 3\% were mildly underweight. Malnutrition were more in children within the age of $0-11$ months, $10 \%$ were moderately underweight, while in 12 17 months of age $2.5 \%$ were severely underweight, children from 36-47 months of age and 48-60 months of age were least affected, $1 \%$ were moderately underweight and $0.5 \%$ were severely underweight respectively.

Table 11. Mid-Upper Arm Circumference based on sex of the children

\begin{tabular}{|c|c|c|c|}
\hline $\begin{array}{l}\text { State of } \\
\text { Nutrition } \\
\end{array}$ & $\begin{array}{l}\text { Male } \\
\text { N }(\%) \\
\end{array}$ & $\begin{array}{l}\text { Female } \\
\text { N }(\%) \\
\end{array}$ & $\begin{array}{c}\text { Total } \\
\text { N }(\%) \\
\end{array}$ \\
\hline Normal & $58(29)$ & $67(33.5)$ & $125(62.5)$ \\
\hline Moderate & $32(16)$ & $35(17.5)$ & $69(33.5)$ \\
\hline Severe & $5(2.5)$ & $3(1.5)$ & $8(4)$ \\
\hline Total & $95(47.5)$ & $105(52.5)$ & $200(100)$ \\
\hline
\end{tabular}

Table 11 presented that $29 \%$ males and $33.5 \%$ of females had normal nutritional status, $16 \%$ and $17.5 \%$ of males and females respectively, were moderately undernourished. While $2.5 \%$ males and $1.5 \%$ females were severely undernourished. 


\subsection{Biochemical Analysis}

Table 12.Malaria status by age group as indicated by presence of malaria parasite

\begin{tabular}{llllll}
\hline $\begin{array}{l}\text { Age Group } \\
\text { (Months) }\end{array}$ & $\begin{array}{l}\text { Presence of Malaria (Male) } \\
\mathbf{N}(\%)\end{array}$ & $\begin{array}{l}\text { Parasite (Female) } \\
\mathbf{N}(\%)\end{array}$ & $\begin{array}{l}\text { Absence of Malaria (Male) } \\
\mathbf{N}(\%)\end{array}$ & $\begin{array}{l}\text { Parasite (Female) } \\
\mathbf{N}(\%)\end{array}$ & $\begin{array}{l}\text { Total } \\
\text { N(\%) }\end{array}$ \\
\hline $0-11$ & $6(3)$ & $4(2)$ & $55(27.5)$ & $31(25.5)$ & $96(58)$ \\
$12-17$ & $3(1.5)$ & $2(1)$ & $13(6.5)$ & $12(6)$ & $30(15)$ \\
$18-23$ & $0(0)$ & $2(1)$ & $4(2)$ & $4(2)$ & $10(5)$ \\
$24-35$ & $1(0.5)$ & $4(2)$ & $3(1.5)$ & $13(6.5)$ & $21(10.5)$ \\
$36-47$ & $0(0)$ & $2(1)$ & $5(2.5)$ & $6(3)$ & $13(6.5)$ \\
$48-60$ & $2(1)$ & $0(0)$ & $3(1.5)$ & $5(2.5)$ & $10(5)$ \\
Total & $12(6)$ & $14(7)$ & $83(41.5)$ & $91(45.5)$ & $200(100)$ \\
\hline
\end{tabular}

Analysis of table 12 represented that malaria parasite was more in females $(7 \%)$ than in males $(6 \%)$. Children within the age range of $0-11$ months had more malaria parasite $3 \%$ males and $2 \%$ female. About $41.5 \%$ of males and $45.5 \%$ females did not have malaria parasite.

Analysis of table 13 presented that $75.5 \%$ were not anaemic, while $24.5 \%$ were anaemic. Amongst those that were anaemic $15 \%$ were mildly anaemic, $6.5 \%$ were moderately anaemic and $3 \%$ were severely anaemic. Anaemia was more (10\%) within ages $0-11$ months, while 48-60 months of age were the least (1\%) anaemic.

Table 13. Hemoglobin level of children, according to their ages

\begin{tabular}{llllll}
\hline $\begin{array}{l}\text { Age Category } \\
\text { (Months) }\end{array}$ & $\begin{array}{l}\text { Normal } \\
\mathbf{N}(\%)\end{array}$ & $\begin{array}{l}\text { Mild } \\
\mathbf{N}(\%)\end{array}$ & $\begin{array}{l}\text { Moderate } \\
\mathbf{N}(\%)\end{array}$ & $\begin{array}{l}\text { Severe } \\
\mathbf{N}(\%)\end{array}$ & $\begin{array}{l}\text { Total } \\
\mathbf{N}(\%)\end{array}$ \\
\hline $0-11$ & $96(48)$ & $13(6.5)$ & $5(2.5)$ & $2(1)$ & $116(58)$ \\
$12-17$ & $22(11)$ & $5(2.5)$ & $2(1)$ & $1(0.5)$ & $30(15)$ \\
$18-23$ & $5(2.5)$ & $3(1.5)$ & $2(1)$ & $0(0)$ & $10(5)$ \\
$24-35$ & $13(6.5)$ & $4(2)$ & $3(1.5)$ & $1(0.5)$ & $21(10.5)$ \\
$36-47$ & $7(3.5)$ & $3(1.5)$ & $1(0.5)$ & $2(1)$ & $13(6.5)$ \\
$48-60$ & $8(4)$ & $2(1)$ & $0(0)$ & $0(0)$ & $10(5)$ \\
Total & $151(75.5)$ & $30(15)$ & $13(6.5)$ & $6(3)$ & $200(100)$ \\
\hline
\end{tabular}

\section{Discussion}

\subsection{Mother's Characteristics}

The results of this study indicates that, the nutritional state of the children was determined with the mothers level of education, because most of the mothers lack formal knowledge of child feeding and care practices. Similar findings have been reported by Kavishe (7). It appears that low education affects many aspects of human life, including demographic and health behaviour. Statistics has consistentlyshown that, education attainment has strong effect on nutrition (8). Similarly, WHO/UNICEF/WFP/SCN Joint statementnoted that mothers education was related to knowledge of good child care practices such as appropriate timing for the meals; and adequate diet to be given to the infants, disease and treatment required, all of which can affect the nutritional outcome of the child (1).

In this study, the majority of the mothers had primary and secondary education, yet under nutrition exists in their children. A research carried out in Lesotho, there is an association between maternal education and child's nutritional knowledge among wealthier household the association was medicated through increased nutritional knowledge (8). However, there was a relationship betweeneducational attainment of the mothers and child's nutritional status which was $(\mathrm{P}<0.05)$.

\subsection{Feeding Practices}

The rate of those exclusively breastfed in this study was high compared to research documented in Tanzania $(9,10)$. Good proportions of children werestill undergoing breastfeeding. However, another research in Owerri metropolis Imo state documented $66.4 \%$ practice of exclusive breastfeeding as against $58 \%$ practice in this study (11). This study was carried out within the same region of Nigeria where Owerri study by Maduforo et al. was done (11)

Early introduction of complementary foods was practiced by mothers. The majority of the mothers were given pap (gruel) mixed with milk or baby milk (infant formula) to their-infant by the time they were 4-6 months of age. It was observed that half of the mothers were following internationally recommended practices which require exclusive breastfeeding up to 6 months. With introduction of complementary foods at 6 months while breastfeeding is continue help in boasting the immune system of the child. Early introduction of complementary foods reduces breast milk consumption (8). As a global public health recommendation, infants should be exclusively breastfedfor the first six months of life to achieve optimal growth, development and health.Thereafter, to meet their evolving nutritional needs, infants should receive safe andnutritionally adequate complementary foods while breastfeeding continues forup to two years of age or beyond (12). Exclusive breastfeeding from birth is possibleexcept for a few rare medical conditions as specified by WHO and UNICEF (13), andvirtually every mother can breastfeed (12).After birth, a child's ability to achieve the standards in growth is determined by the adequacy ofdietary intake (which depends on infant and young child feeding and care practices and foodsecurity), as well as exposure to disease (14). Undernutrition and infection are intertwined in asynergistic vicious cycle. 
Therefore, support to quality child feeding practices (breastfeeding andcomplementary feeding) and improvement of household food security, together with diseaseprevention and control programmes, are the most effective interventions that can significantly reduce stunting and acute malnutrition during the first two years of life (12).

This "window of opportunity" to prevent undernutrition is the same period when the recommendedinfant and young child feeding practices are applied: exclusive breastfeeding for the first 6 months,continued breastfeeding to 2 years or beyond together with adequate, safe, and appropriatecomplementary feeding from 6 to 23 months. Therefore, sub-optimal breastfeeding andcomplementary feeding practices put children in developing countries at high risk for undernutritionand its associated outcomes which are far-reaching and difficult to reverse later in life (12). Many studieshave also shown that the greatest impact for interventions can be seen among children less than twoyears of age (15). Taking full advantage of this "window of opportunity", optimal breastfeeding andcomplementary feeding practices together can allow children to reach their full growth potential andprevent irreversible stunting, as well as acute undernutrition.(12).

\subsection{Care Resources}

Household care, resource were found to have association with children's nutritional status and care received and this may limit mothers ability to feed their children appropriately.The care resources included; educational level, occupation, family income, family size, (household size). The study revealed that large household have significant $(\mathrm{P}<0.05)$ influence on the nutritional status of the children than smaller household. Nutrition education improves caregiver practices through; provision of information about local foods, industrially-processed complementary foods, and in homefortification of foods to caregivers, promotion of appropriate feeding behaviours and use of multiple channels to educate and counsel caregivers (from communication through massmedia to individual counselling) $(16,17)$.Caregivers must be given information and support on both breastfeeding and complementary feeding, including information about locally available foods and additional options for improving both the quality of the available foods and the feeding practices themselves (12).

\subsection{Nutritional Status}

The nutritional status and feeding practices of children aged 0-60months were assessed. Children between 0-11 month and 12-17 months had this highest rate of malnutrition. From this study the prevalence of under nutrition was:

Wasting is a measure which indicates low weight-forheight below -2SD (18). The results of the study showed that $19 \%$ of the under five children were moderately wasted and $6 \%$ were severely wasted. This is higher than that observed by Tanzania demographic and health survey, which was 7\% moderately wasted and $1 \%$ severely wasted (10). This also differs from UNICEF report in Nigeria, (14\%) (19). However, UNICEF report (19) was based on healthy heterogeneous samples while this present study was based on homogenous sample found in a particular area of Nigeria and already admitted in the hospital for treatment and management. Wasting indicates defect in tissues and fat mass compared with amount expected in a child of the same height or length and may result either from failure to gain weight or from' actualweight loss. This study found the highest prevalence of wasting $12 \%$ to be among children between 0-11 monthsof age. The failure to receive adequate nutrition could lead to frequent illness causing loss of weight might contribute to this.

Stunting (low height-for-age) this indicates a child whose height-for-age is below -2SD from the median of the reference population. Itis also an indicator of either acute or chronic under-nutrition. Total stunting (severe+moderate) in this study was $28.5 \%$. This is below Tanzania demographic and health survey (TDHS) studies reported in 1999 (43.8\%) (10). However, it is also below UNICEF 2010 study in Nigeria reported (41\%) in 2012 (19). In this study about $13 \%$ of children $0-11$ months of age were stunted. Moreover exclusive breastfeeding was not practiced in $29 \%$ of the children. Apart from other physical and physiologicaldimension, stunting usually result from prolonged inadequate intake of food as well as disease making infant to have a low height for their age. This observation suggests that nutritional problem start at very early age and it is the most vulnerable period for children.

Underweight (low weight-for-age) is an indicator of either acute or chronic undernutrition. The prevalence of underweight (severe + moderate) in the study was $27 \%$. This is similar to $28.5 \%$ reported by URT and UNICEF in Tanzania (10), but more than UNICEF report (14\%) in Nigeria (19). In this study children between 36-47 months and 48-60 months showed the least prevalence of underweight, while that of 0-11 months and 12-17 months showed the highest prevalence of underweight. Low weight-for-age at the age of $0-11$ months is due to stunting rather than wasting. This low rate of underweight age group 48-60 months is likely to be due to the fact that children at this age are old enough to eat a variety of foods including normalfamily meals.

Nutritional factors are the most cause of iron deficiency in infancy and childhood. The main etiologies of iron deficiency at this period of life cycle are (20):

1. Decreased iron stores at birth (preterm infants, twins,prenatal bleeding etc)

2. Inadequate iron supply (reduced dietary iron and / or low bioavailability of dietary iron).

3. Increase iron losses (gastrointestinal blood loss, and diarrhea).

The rate of anaemia in this study was high in children 011 months, $6.5 \%$ mildly anaemic, $2.5 \%$ moderately anaemic and $1 \%$ severely anaemic. This could be attributed to the 
presence of malaria parasite in this children. Nutritional iron deficiency anaemia is less prevalent in older children because of their slower growth rate and more varied diet (20).

The prevalence rates of malaria parasite were males $(6 \%)$ and females $(7 \%)$ respectively. No significant relationship was found between illness and nutritional statuses of the children. There is a significant relationship between normal, mild,moderate and severely malnourished children from 6 60 months admitted in mother of Christ hospital.

\section{Conclusion}

In this study on prevalence of severe acutemalnutrition in children from $6-60$ months admitted in mother of Christ Specialist Hospital Ogui, Enugu. Results indicated that malnutrition is a problem among children in the area. The prevalence of malnutrition such as wasting, stunting and underweight was high within the ages of 0-11 months and 12- 17 months. Child feeding practices were inadequate. Mother's characteristics and household feeding characteristics appear to influence children's nutritional status. Effort to improve feeding practices and to relieve the constraints to the adoption of exclusive breastfeeding and optimal feeding practices will have significant effects on child nutritional status in the population.

\section{References}

[1] WHO/CDC/WCHS (2007), prevalence of global acute malnutrition (GAM) and Severe acute malnutrition (SAM). WHO Geneva

[2] Nigeria Demographic and Health Survey (2013). National Population Commission Federal Republic of Nigeria Abuja, Nigeria. MEASURE DHS, ICF Macro Calverton, Maryland, USA,

[3] Government of Federal Republic of Nigeria (2010). $M D G$ Report 2010: Nigeria Millennium Development Goals. Abuja, Nigeria: Government of Federal Republic of Nigeria.

[4] Nigeria Demographic and Health Survey (2003). National Population Commission Federal Republic of Nigeria Abuja, Nigeria. MEASURE DHS, ICF Macro Calverton, Maryland, USA.

[5] Nigeria Demographic and Health Survey (2008). National Population CommissionFederal Republic of Nigeria Abuja, Nigeria. MEASURE DHS, ICF MacroCalverton, Maryland, USA,

[6] Hans-Konrad B. and Jürgen G. E (2007). Diagnosis of nutritional anemia -laboratory assessment of iron status in NutrionalAnaemia Edited by Klaus Kraemer SIGHT AND LIFEBasel, Switzerland.
[7] Kavishe, F.P. (1993): Nutrition Relevant Action in Tanzania Food and Nutrition Centre 20th Anniversary 1973-1993 monograph series No.1, UN-ACC/SCN country case study for the XV congress of the international union of the nutrition sciences September 26 to October 1, 1993, Adelaide. Pp 180-230.

[8] Kulwa M. Beata, Matkinabo D. and Kissa B. (2006), constraints on good child care practice and nutritional status in urban Dares - Salgam, Tanzania Food and Nutrition Bulletin, Vol. 27 No 3.

[9] Santo I. Victoria Ca, Martina J. and Peter G.H. (2006), Nutrition counseling increase weight gain among Tanzania children. Food and Nutrition bulletin Vol. 28, No.

[10] URT and UNICEF (1998), The situation analysis of women and children in Tanzania Dares-Salaam Pp. 140. 154.

[11] Maduforo, A.N, Ubah N.C and Obiakor- Okeke P.N. (2013) The Practice Of Exclusive Breastfeeding By Lactating Women In Owerri Metropolis, Imo State, Nigeria. Glo. Adv Res. J. Med. Med. Sci. January 2013 2(1): 013-019 http://www.garj.org/garjmms

[12] UNICEF(2012). Infant and Child FeedingNutrition Section, Programmes, UNICEF New York

[13] WHO/UNICEF (2008). Acceptable medical reasons for use of breast-milk substitutes.

[14] Scrimshaw NS (1968). Interactions of nutrition and infection. Geneva: World Health Organization. 1968.

[15] Dewey K. and Adu-Afarwuah S. (2008). Review article: Systematic review of the efficacy and effectiveness of complementary feeding interventions in developing countries. Maternal and Child Nutrition 2008: 4: 24-85.

[16] Guldan G.S., Fan H.C., Ma X., Ni Z.Z., Xiang X. \& Tang M.Z. (2000) Culturally appropriate nutrition education improves infant feeding and growth in rural Sichuan, China. Journal of Nutrition: 130: 1204-1211.

[17] Bhandari N., Mazumder S., Bahl R., Martines J., Black R.E. \&Bhan M.K. (2004) An educational intervention to promote appropriate complementary feeding practices and physical growth in infants and young children in rural Haryana, India. Journal of Nutrition: 134: 2342-2348.

[18] WHO (1995), Physical Status, the use and interpretation of anthropometry. WHO Expert committee technical report series No. 854, Geneva Switzerland, P. 125.

[19] United Nations Children's Fund (UNICEF) (2012)The State Of The World's Children 2012 United Nations publications www.unicef.org/sowc2012

[20] Manuel O., Tomas W., Eva H. and Fernando P. (2006), Micronutrient in health and disease. Institute of Nutrition and' Food technology (IWFT) University Chile, Santiago. British Medical Bulleting. Pp 4-6. 